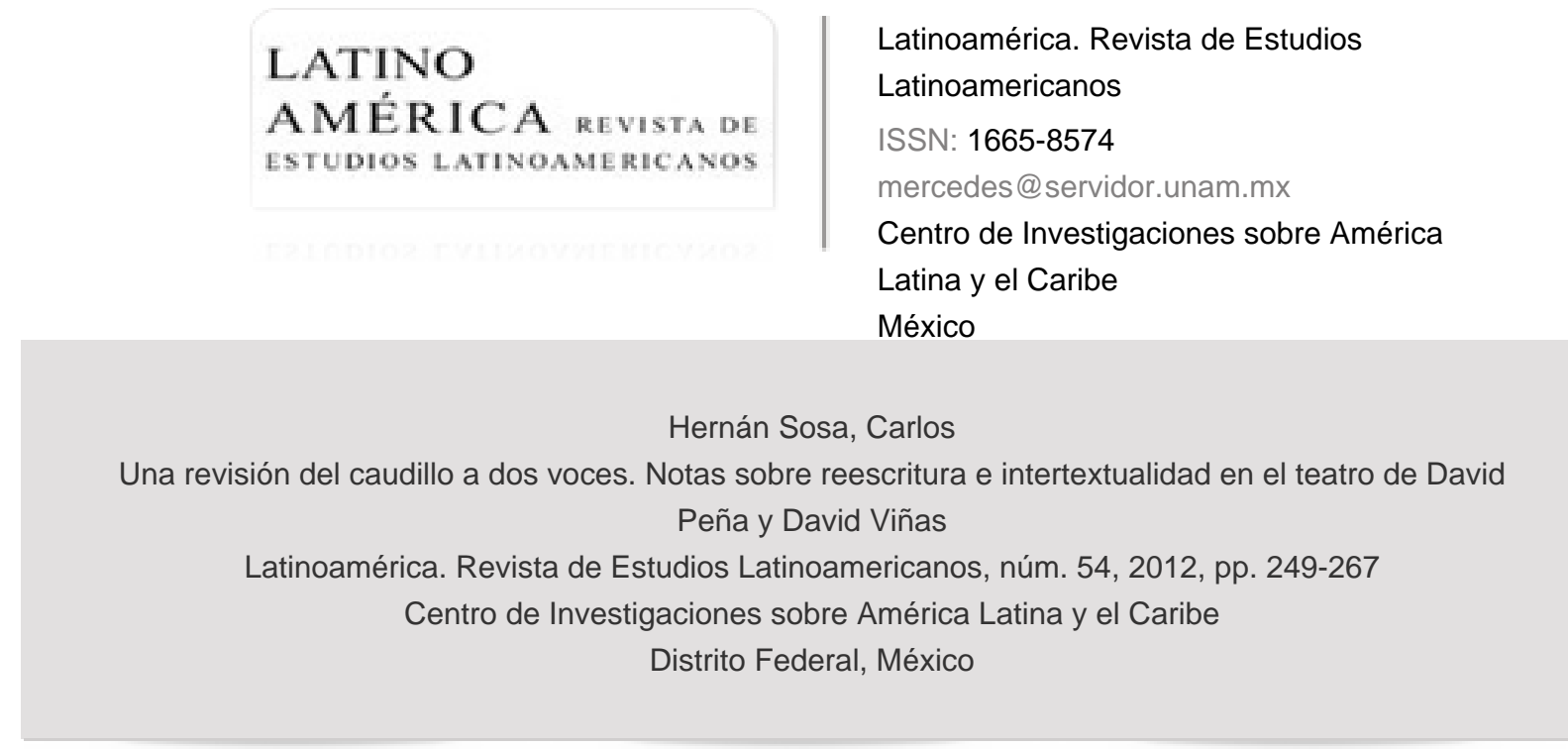

Disponible en: http://www.redalyc.org/articulo.oa?id=64023055010

Cómo citar el artículo

- Número completo

- Más información del artículo

- Página de la revista en redalyc.org

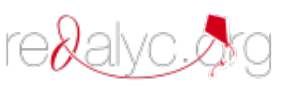

Sistema de Información Científica

Red de Revistas Científicas de América Latina, el Caribe, España y Portugal Proyecto académico sin fines de lucro, desarrollado bajo la iniciativa de acceso abierto 


\section{Una revisión del caudillo a dos voces. Notas sobre reescritura e intertextualidad en el teatro de David Peña y David Viñas}

Carlos Hernán Sosa*

RESUMEN: Este trabajo analiza la recuperación que dos obras teatrales realizan de una misma situación histórica relevante de la historia argentina: el levantamiento militar (1828) por el que se fusiló al caudillo Manuel Dorrego. Ambos textos: el Dorrego de David Peña (1909), y el Dorrego de David Viñas (1974), presentan vínculos intertextuales mediante los cuales han revisado algunos temas decisivos para la cultura política argentina (el caudillismo, el populismo, la participación del ejército en la política). Por otra parte, al reinterpretarse cada pieza en su contexto, se recuperan alusiones veladas a la realidad contemporánea que los textos cuestionaban indirectamente apelando a la relectura histórica.

Palabras ClavE: Teatro argentino, Drama histórico, David Peña, David Viñas, Manuel Dorrego, Intertextualidad.

ABSTRACT: This work analyzes two theater works about an episode of Argentine history: the military rise of 1828 where the caudillo Manuel Dorrego was shot. Both texts, Dorrego by David Peña (1909) and Dorrego by David Viñas (1974), have intertextual bonds by means of which they have reviewed some decisive subjects for the Argentine political culture -caudillismo, populism, participation of the army in the policy-. On the other hand, when reinterpreting each piece in its context, there have been recovered veiled references to the contemporary reality which the texts questioned, indirectly appealing to a historical re-reading.

Key words: Argentine theater, Historical drama, David Peña, David Viñas, Manuel Dorrego, Intertextuality.

Facultad de Humanidades, Universidad Nacional de Salta, Argentina (chersosa@hotmail.com) 
Carlos Hernán Sosa

Mucha gentuza a las honras de Dorrego; litografías de sus cartas y retratos; luego se trovará la carta del Desgraciado en las pulperías, como las de todos los desgraciados que se cantan en las tabernas. Esto es bueno; porque asi el padre de los pobres, será payado con el capitán Juan Quiroga y los demás forajidos de su calaña. iQué suerte! Vivir y morir indignamente y siempre con la canalla.

Carta de Salvador María del Carril a Juan Lavalle. ${ }^{1}$

- a figura histórica del caudillo argentino Manuel Dorrego ha sido retomada desde lo discursivo por una gama variada de textos - documentales, historiográficos, literarios, folclóricos - y ha cristalizado en un conjunto de representaciones contrapuestas. Estas construcciones, tan oscilantes en su ponderación, recorren un arco que avanza sin medias tintas desde "la cabeza de la hidra" - un ícono injurioso y beligerante construido por los detractores contemporáneos del caudillo, y abonado luego por la historiografía liberal argentina-, hasta la figura del "mártir de Navarro"2 —-mediante la cual intentaron redimirlo algunos historiadores revisionistas-, y son las marcas más notorias de un entramado ideológico en el cual es perceptible la actitud deliberada de arriesgar interpretaciones del pasado nacional argentino, sin perder de vista las necesidades y las contingencias de cada presente.

1 El epígrafe es un fragmento de la carta que Salvador María del Carril, uno de los principales ideólogos y conspiradores de la revolución de diciembre que destituyó al caudillo bonaerense, le escribió a Juan Lavalle el 20 de diciembre de 1828, días después del fusilamiento de Dorrego. El texto ha sido incorporado, como documento núm. 29, en el "Apéndice documental" que se adjunta en el libro de Rodolfo Ortega Peña y Eduardo Luis Duhalde, El asesinato de Dorrego. Poder, oligarquí y penetración extranjera en el Río de la Plata, Buenos Aires, Peña Lillo editor, 1973, p. 134. Las cursivas están en el original.

2 Navarro es el pueblo, ubicado al sur de la ciudad de Buenos Aires, donde las tropas de Juan Lavalle fusilaron al coronel Dorrego, en diciembre de 1828. 
A lo largo de este trabajo nos proponemos analizar dos versiones literarias que se concentraron en dicho personaje y las circunstancias históricas que rodearon su existencia, aquellas que nos ha legado el teatro argentino en dos contextos puntuales: el Dorrego de David Peña, en 1909, y el Dorrego de David Viñas, en 1974. Relacionadas intertextualmente, ambas obras proponen revisiones de esta figura y una serie de nudos claves para desbrozar conflictos determinantes en la historia argentina: el caudillismo, la participación política popular, el papel del ejército en el terreno político, etc. ${ }^{3}$ A su vez, refractados hacia sus contextos de emergencia, los planteamientos de cada pieza terminarán por pro-

3 Con el fin de que se puedan recuperar las principales referencias históricas del trabajo, sobre todo en el caso de los lectores no familiarizados con estos episodios de la historia argentina, bosquejamos a continuación algunos datos de la biografía de Dorrego, enmarcada en las luchas entre posiciones centralistas y federales que polarizaron el derrotero de construcción institucional y política de Argentina desde mediados del siglo xIx. Nacido en Buenos Aires, en 1787, Manuel Dorrego fue un militar que participó en la guerra de independencia, donde luchó bajo las órdenes de Manuel Belgrano en las campañas al Alto Perú. Por conflictos con las decisiones políticas del Director Supremo Juan Martín de Pueyrredón, fue desterrado y abandonó el país en 1816. Durante su exilio vivió en Estados Unidos, donde conoció y estudió el régimen democrático federal del gobierno norteamericano, que intentaría implementar en Argentina, tras su regreso en 1820. Inmerso desde entonces con mayor ahínco en la participación política, ocupó cargos legislativos como representante de la facción federal porteña, y llegó a ser nombrado gobernador de la provincia de Buenos Aires en agosto de 1827, para suceder en el cargo a Bernardino Rivadavia, por entonces máximo representante del centralismo porteño. Desempeñaba este cargo cuando, en diciembre de 1828, una revolución gestada en el seno del sector unitario porteño fomentó un levantamiento militar capitaneado por Juan Lavalle, quien acababa de regresar a Buenos Aires victorioso de la guerra contra el Brasil. Obligado a huir a la campaña, Dorrego fue apresado y fusilado por las fuerzas de Lavalle, sin juicio previo militar u ordinario, el 13 de diciembre de 1828. Su muerte, tradicionalmente ha sido interpretada como el inicio de una nueva etapa en la historia argentina, especialmente por la virulencia de las guerras civiles que se desencadenaron de forma consecutiva. La desaparición de la figura de Dorrego del mapa político del momento también ha sido leída historiográficamente como un allanamiento para la concreción de los intereses de los sectores ganaderos bonaerenses, que llevaron inmediatamente al poder a Juan Manuel de Rosas en 1829, año en el que se inició su larga dictadura, prolongada hasta su caída en 1852, a manos de un ejército de fuerzas aliadas comandado por Justo José de Urquiza. Con este episodio se iniciaba un nuevo periodo, en el que se superaban en buena medida las guerras civiles y se facilitaba, entonces, la organización política e institucional definitiva del territorio y el gobierno nacionales en Argentina. 
Carlos Hernán Sosa

poner, de manera complementaria, una lectura cifrada sobre las eventualidades de la contemporaneidad.

La poco transitada producción de David Peña parece reservar un lugar privilegiado para sus conferencias del año 1903 -pronunciadas en la Universidad de Buenos Aires, y compiladas luego en el tomo Juan Facundo Quiroga-, mientras continúan relegados otros aspectos concernientes a su poesía y a su escritura dramática. ${ }^{4}$ En este último rubro, que aquí nos interesa analizar en particular, el autor ha sido reconocido más de una vez como uno de los pioneros en la promoción del drama histórico nacional en Argentina. Efectivamente, varias de sus obras: Facundo (1906), Dorrego (1909), Liniers (1917), Alvear (1924), 5 tienen temática histórica y ya postulan desde el título la revisión de dicha materia, desde una perspectiva ceñida al abordaje de ciertos sujetos "neurálgicos" representativos. ${ }^{6}$

En este sentido, el tratamiento de la figura de Quiroga, desde la lectura y los aportes documentales renovadores que David Peña recupera en su Juan Fa-

4 El escritor salteño Joaquín Castellanos ha dejado una semblanza sobre su amigo David Peña, donde pasa revista a la vida del escritor santafesino y su producción literaria; en ella, significativamente ponderaba la obra dramática de Peña como la de mayor valía, por lo que le aconsejaba afianzar esa vertiente creativa. Véase Joaquín Castellanos, "David Peña", en Obras literarias, Buenos Aires, Imprenta del Honorable Senado de la Nación Argentina, 2000, pp. 57-62.

5 La producción de David Peña es abundante, incluye obras de teatro, narrativa y poesía, además de otras de alcance histórico como Juan Facundo Quiroga e Historia de las leyes de la Nación Argentina. Un comentario sobre su escritura dramática, que nos merece especial atención en este trabajo, puede encontrarse en Raúl Héctor Castagnino, Literatura dramática argentina. 1717-1967, Buenos Aires, Pleamar, 1968, pp. 106-108; y Ángela Blanco Amores de Pagella, Motivaciones del teatro argentino del siglo xx, Buenos Aires, Ediciones Culturales Argentinas, 1983, pp. 179-181.

6 Como dato anecdótico pueden consultarse las reseñas que ha dejado Mariano Bosch sobre la repercusión de algunas de las obras de Peña (Próspera, Inútil, Dorrego, Liniers) en el ambiente de los teatristas porteños de principios del siglo xx. Véase Mariano Bosch, Historia de los orígenes del teatro nacional argentino y la época de Pablo Podestá, Buenos Aires, Solar/Hachette, 1969. 
cundo Quiroga -texto que entronca en la serie de enmiendas apendiculares del Facundo de Domingo Faustino Sarmiento (pensemos en las "Notas" de Valentín Alsina o en "Facundo y su biógrafo" de Juan Bautista Alberdi)-, hasta la escritura dramática de "otro" Facundo,7 puede resultar paradigmático, ya que se reconoce en ambos intentos una pretensión correctiva de "las deficiencias históricas", en este caso del texto de Sarmiento, a partir de una nueva interpretación con explícitas pretensiones de profesionalidad y tendiente a una escritura menos visceral de la historia nacional argentina. ${ }^{8}$

La concepción del teatro en David Peña, en relación con el drama histórico, también parece acercarse a una función propedéutica, de necesaria enmienda o reparación históricas. ${ }^{9}$ La propia asunción de su escritura dramática insinúa los pasos previos de la labor del historiador: la recopilación de datos y de documentos, la confrontación entre las fuentes conservadas y el posterior debate de hipótesis; estadios a partir de los cuales se abrirá paso, inclusive, a varios juegos intertextuales, que salen a la luz tras la lectura de cierta documentación, como es el caso de la correspondencia privada que intercambiaron algunos de los personajes históricos que la escritura dramática recupera (los militares Manuel Dorrego y Juan Lavalle, el jurista Salvador María del Carril, el sacerdote Julián Segundo de Agüero), durante las acciones políticas que se

7 El texto de este otro drama histórico de David Peña puede consultarse como importante complemento de las representaciones de sujetos emblemáticos de la historia nacional argentina que emprende el autor. Véase David Peña, "Facundo. Drama histórico en cuatro actos", en Bambalinas. Revista de actualidades teatrales y artísticas, año I, núm. 38, Buenos Aires, 21 de diciembre, 1918.

8 Para ampliar estas concepciones de David Peña, sobre la escritura de la historia y sus postulaciones acerca de la necesidad de revisar la historia nacional, resulta importante la consulta del prólogo que abre Juan Facundo Quiroga, donde el autor esboza una línea interpretativa de la historia argentina del siglo xix, en clave política, a la vez que anticipa enmiendas al Facundo de Sarmiento y sugiere una nueva metodología para el abordaje de los estudios históricos. Véase David Peña, Juan Facundo Quiroga, Buenos Aires, Hyspamérica, 1986, pp. 9-11.

9 El propio autor reconocía este punto, en una carta dirigida a Ramón J. Cárcano, donde le confesaba: "Ocurrióseme seguir utilizando el teatro para la divulgación de la verdad histórica". Citado en Blanco Amores de Pagella, op. cit., p. 181. 
Carlos Hernán Sosa

representan en su Dorrego, y que el autor ha revisado y reacondicionado bajo el imperio de las interpretaciones personales que operan en esta pieza. ${ }^{10}$

La figura de Manuel Dorrego le permite a David Peña reconsiderar algunos ejes medulares - con una larga discusión historiográfica previa - que orbitan alrededor de la destitución y el fusilamiento del personaje, y propician el examen de las falencias concomitantes de un fallido proyecto político nacional en Argentina, que terminó derrumbándose a partir de las propias inherencias retardatarias del federalismo y de los aportes mezquinos de la conspiración unitaria. En este juego de pesos políticos relativos e inestables, muy representativo del unanimismo decimonónico de las facciones en lucha, que la óptica modelizadora de David Peña aglutinó en las figuras señeras de Bernardino Rivadavia y Juan Facundo Quiroga - como paradigmas del unitarismo y del federalismo decimonónicos argentinos-, bascula y se desestabiliza la presencia de Manuel Dorrego en la acción pública de Argentina de mediados del siglo xIx. ${ }^{11}$

Cuando el autor analizaba, tangencialmente, el episodio final del gobierno de Dorrego, desde la percepción y los utillajes metodológicos de la escritura histórica en Juan Facundo Quiroga, esbozó un tibio resarcimiento para el caudillo bonaerense, más pendiente de los móviles ilegítimos del ajusticiamiento que de la política - defensora del "autonomismo de Buenos Aires" - que había emprendido Dorrego durante su gobierno. ${ }^{12}$ Sin embargo, al momento de retomarlo como personaje literario en su drama histórico, tuvo más recaudos y calibró una interpretación claramente reivindicadora de dicha figura, decisión que

${ }^{10}$ Entre los juegos intertextuales notorios se reconoce la utilización de frases del parte en el cual Juan Lavalle comunicaba oficialmente el fusilamiento de Manuel Dorrego, que son empleados como los parlamentos de dicho personaje en la pieza. Véase David Peña, "Dorrego. Drama histórico en cuatro actos", en Bambalinas. Revista teatral, año II, núm. 75, Buenos Aires, 13 de septiembre, 1919, p. 24. Además, Lamadrid en el final del drama lee en sus intervenciones fragmentos de las cartas que Dorrego escribe en escena, para despedirse de sus familiares y amigos (ibid., p. 32), y que actualmente se conservan en los archivos documentales. Consultar, en este sentido, el "Apéndice documental" del libro de Ortega Peña y Duhalde, op. cit., pp. 83-140.

${ }^{11}$ Para este aspecto, resulta necesario considerar las postulaciones, que sobre las disidencias políticas, durante las guerras civiles argentinas, ha desarrollado el autor en su Juan Facundo Quiroga. Véase Peña, Juan Francisco Quiroga...

${ }^{12}$ Consultar David Peña, "Dorrego. Drama histórico..., pp. 98-101. 
organizaba la pieza casi montándola sobre una tesis rectora: Dorrego fue una víctima, incuestionable, del complot político.

Esta construcción ficcional del personaje lo trata como un representante popular genuino, que logra encauzar los descontentos hacia la presidencia de Rivadavia, en el comienzo de la obra. La misma, significativamente se inicia, entonces, en la sala de redacción de El Tribuno - uno de los diarios que contribuyó en el desprestigio del presidente- por la cual desfilan entusiastas simpatizantes del futuro gobernador, especialmente algunos negros y carniceros. Estas circunstancias, que instalan uno de los tópicos críticos más recurrentes en torno de Dorrego -la demagogia y su tendencia al populismo-, servirán para organizar el rechazo de los representantes unitarios, quienes lo perciben como: "iAdulador de la plebe, [que] ha seguido siempre con su palabra hueca las tornadizas aventuras y gustos de la multitud", ${ }^{13}$ y la consecutiva reivindicación, pues el texto refuerza, desde el comienzo, la idea de una auténtica adhesión general al caudillo que no se limita a los sectores sociales populares y desprotegidos. ${ }^{14}$

Además, en una poco atinada elección, desde el punto de vista escénico, frente a las injurias de sus detractores el protagonista se encargará de verbalizar, con reiteración, un curriculum vitae que lo ennoblece desde el accionar político. El personaje hará una prolija enumeración de sus aciertos en el terreno de la conducción: la concreción de la paz con el Brasil, el diálogo fructífero con los gobernadores del interior, acelerar las pensiones de guerra, dictar las reglamentaciones para los hospitales de la ciudad, nombrar profesores en la Universidad de Buenos Aires, etc. Por ello, cuando ya advierte cercana la conspiración, el caudillo federal exclama con una agudeza testimonial excesiva -sin duda, históricamente descalibrada - para su denuncia:

${ }^{13}$ Ibid., p. 20.

${ }^{14}$ En este sentido, además del séquito de Dorrego -integrado por Manuel Moreno, Cavia y Fray Francisco de Paula Castañeda - no parece accesorio subrayar, por ejemplo, una acotación escénica intencional que aclara, refiriéndose al grupo que irrumpe en escena apoyando la asunción del gobernador bonaerense, la presencia de "muchas personas bien vestidas". Ibid., p. 11. 
Carlos Hernán Sosa

Si he escalado el poder ha sido por medios dignos, lícitos, y puedo legar a mi partido la satisfacción de haber adoptado en un año una serie de medidas progresistas, humanitarias y patriotas [...]. iA un hombre de estos títulos no se le voltea con motines ni se le insulta por medio de labios extranjeros! $!^{15}$

Esta "perspectiva histórica desfasada", que vehiculiza -y desnuda - la apuesta política de la exégesis histórica de Peña, permite también los vaticinios adversos del protagonista ya en trance de muerte, quien improvisa preanuncios sobre la fama de su verdugo, el general Juan Lavalle, como consecuencia de este accionar desgraciado, que terminará mancillando a toda la sociedad argentina:

Mi muerte llenará de oprobio y de vergüenza su nombre y su memoria. [...] iAnúnciele el desprestigio en que vamos a caer por su culpa todos los argentinos, todos! Y anúnciele principalmente que aunque yo no quiera, vendrán ríos de sangre a vengar el derramamiento de la mía. ${ }^{16}$

La "impostada prospectiva futurista" de la pieza es otra evidencia de la urgencia de David Peña por reinterpretar la historia nacional argentina que venimos comentando. La recuperación de las complejas figuras de caudillos en sus piezas - en el contexto de un incipiente revisionismo historiográfico, en cuya vertiente también ha sido catalogado como un precursor, ante todo por su libro dedicado a exhumar la vida de Quiroga $-{ }^{17}$ propone una perspectiva renovadora más ajustada a los propósitos de estudio y de análisis históricos "científicos" que ya había programado en Juan Facundo Quiroga. Esta entusiasta redención de Dorrego que practica David Peña, donde incluso ameniza o reserva en un prudente olvido sus propias consideraciones anteriores - tibias y adversas- sobre el personaje, es quizá un índice de confluencia con el carácter muchas veces maniqueo del revisionismo argentino, en cuyos remotos oríge-

15 Ibid., p. 26.

${ }^{16}$ Ibid., p. 31.

${ }_{17}$ Para este punto consultar: Blanco Amores de Pagella, op. cit., pp. 179-181 y Alfredo Rubione, "Enrique Larreta, Manuel Gálvez y la novela histórica", en Noé Jitrik [dir.], Historia crítica de la literatura argentina, vol. 6, "El imperio realista" (directora del volumen María Teresa Gramuglio), Buenos Aires, Emecé, 2002, pp. 282-285. 
UNA REVISIÓN DEL CAUDILLO A DOS VOCES. NOTAS SOBRE REESCRITURA E INTERTEXTUALIDAD EN EL TEATRO ...

nes se perfilaban ya intransigencias insobornables, en materia de entronización de algunos representantes decimonónicos del federalismo.

III

Cuando en 1974 David Viñas encabezó su Dorrego, es decir su versión personal sobre los mismos acontecimientos, con la dedicatoria: "A la memoria de David Peña, fundador", indiscutiblemente explicitaba un afán genealógico con la escritura literaria y la apuesta revisionista de David Peña.

Durante el desarrollo de la intriga, David Viñas también nos recorta las acciones de su drama político argentino ante el telón de fondo de la disputa entre las dos falanges ideológicas fuertes del siglo xIx: la unitaria y la federal; ${ }^{18}$ una percepción que resulta para el espectador demasiado fácilmente reconocible, en un comienzo, pero que tendrá luego deslindes más complejos que tornarán engañosa, y tal vez menos relevante, esta segregación manifiesta de los primeros pases escénicos.

Al momento de optar por una representación de la figura de Dorrego, dentro de la generosa gama ya disponible, ${ }^{19}$ el texto parece defender concienzuda-

${ }^{18}$ Una lectura que pasa revista a la historia de esta construcción de bandos, a partir de la consideración específica que recibió la figura de Juan Manuel de Rosas, es la que ofrece Clementi. Véase Hebe Clementi, Rosas en la bistoria nacional, Buenos Aires, La Pléyade, 1970. En el mismo sentido, es útil la lectura del reciente trabajo de Lelia Area, Una biblioteca para leer la Nación. Lecturas de la figura Juan Manuel de Rosas, Rosario, Beatriz Viterbo, 2007. Otra versión también más actualizada, que estudia los modos de conformación de lo que él denomina "ficciones orientadoras", desde comienzos del siglo xix y hasta la década del 1880, es la que proporciona Shumway. Véase Nicolás Shumway, La invención de la Argentina. Historia de una idea, Buenos Aires, Emecé, 1995. Por último, puede revisarse todavía con provecho una ponderación más ajustada a la historiografía tradicional argentina en el trabajo de Enrique Barba, Unitarismo, federalismo, rosismo, Buenos Aires, CEAL, 1982.

${ }^{19}$ David Viñas disponía de numerosos antecedentes con los cuales inspirarse y urdir una lectura propia: las que había realizado la historiografía sobre el asunto, especialmente los relatos de las historias nacionales de Argentina: la de perspectiva liberal, dirigida por Ricardo Levene, "La sublevación del $1^{\circ}$ de diciembre de 1828 y los gobiernos de Lavalle y Viamonte", en Academia Nacional de la Historia, Historia de la Nación Argentina, Buenos Aires, El Ateneo, 1950, vol. VII, 
Carlos Hernán Sosa

mente los matices de la contradicción como elemento definitorio de una nueva imagen para el protagonista, pareciera incluso desconfiar del magisterio de David Peña. Es esta inherencia polifacética la que se refuerza también, en el plano privado y en el público, como un conflicto irresuelto que hará vacilar la orientación de los matices verdaderamente trágicos de la obra, encabalgando el drama personal con el del estadista.

Los primeros adjetivos, que resuenan calificando al personaje, por ejemplo, puntualizan su relación con la sociedad, la cual aparece designada a partir de un ideologema proteico caro a la historia política argentina: el pueblo. El primer contacto de Dorrego con los sectores populares se produce con los negros, tal como había ocurrido en el drama anterior de David Peña, quienes lo alientan en su asunción como gobernador de la provincia de Buenos Aires.

Se puede apreciar en estas escenas todo un despliegue que nos acerca las posibilidades del paternalismo político, plasmado en la interacción directa sin mediaciones del gobernador con la gente - en un diálogo que reproduce otro idéntico de la pieza de David Peña-. En este encuentro del líder con sus adeptos políticos, Dorrego reconoce metódicamente a cada integrante del grupo y, haciendo gala de su manejo de información de índole privada, los interroga en

pp. 227-271, y la de perspectiva rosista, escrita por José María Rosa, Historia Argentina, t. IV, "Unitarios y federales", Buenos Aires, Oriente, 1965; también tenía a su alcance los cuestionamientos revisionistas presentes en la obra de Arturo Jauretche, Política nacional y revisionismo histórico, Buenos Aires, Peña Lillo editor, 1982. Por último, existe un texto, temporal e ideológicamente próximo, a la escritura del Dorrego de Viñas: El asesinato de Dorrego de Rodolfo Ortega Peña y Eduardo Luis Duhalde ya citado, que lleva el sugestivo subtítulo "Poder, oligarquía y penetración extranjera en el Río de la Plata" y cuenta con dos ediciones en 1965 y 1973. El mismo se publicó con un importante apéndice documental, en el que abrevan varias de las argumentaciones, claramente reivindicadoras de las figuras de Dorrego y Rosas, que sustentan el libro. Es interesante subrayar que la segunda edición de esta obra, perteneciente a dos autores argentinos considerados generalmente como "revisionistas de izquierda" de la década de 1970, se abre con una carta legitimadora del presidente derrocado Juan Domingo Perón quien, desde el exilio en Madrid, agradece a los autores el regalo de un ejemplar de la primera edición del libro. En ese sentido, no parece menor señalar el dato de que uno de los autores del libro, Rodolfo Ortega Peña, fue un militante peronista comprometido que murió asesinado por la Alianza Anticomunista Argentina -más conocida como Triple A—en 1974, el mismo año de publicación del Dorrego de Viñas. 
UNA REVISIÓN DEL CAUDILLO A DOS VOCES. NOTAS SOBRE REESCRITURA E INTERTEXTUALIDAD EN EL TEATRO ...

detalle sobre las menudencias de la vida cotidiana, exhibiendo un "interés" por la historia individual de cada sujeto. ${ }^{20} \mathrm{Al}$ punto que es el candombe de negros en el que, usufructuando las prerrogativas de este vínculo tan cercano como no institucionalizado con la autoridad, terminará dándole consejos de orden político al gobernante:

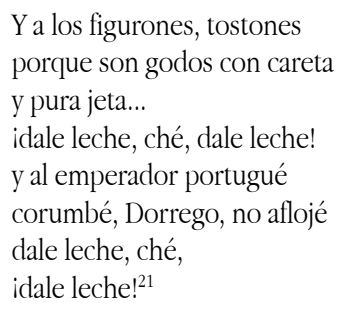

Muchas de las aristas dispares en esta elaboración discursiva del personaje histórico alcanzan en el monólogo final de nuestra pieza, donde se condensan varios matices enfrentados, una conmovedora síntesis facilitada por la técnica discursiva del fluir de conciencia. Así, ante las desesperantes circunstancias se explaya el protagonista:

Soy un tábano que se les metió por los oídos. Dorrego, Dorrego [...]. Y les zumbo dentro de la cabeza. Dorrego peligro, Dorrego excesivo, Dorrego amado por todos [...]. Calma, Dorrego. Honorable, Dorrego. Coronel, Dorrego. Héroe, Dorrego [...]. ¿Tiemblo? Sí, sí, sí. No [...]. Ese tábano se ha pasado a mi cabeza [...]. No, no: me insulta: prepotente, demagogo, petulante. Uno, dos, tres, insultos. Puedo ahogarlo y me marca más insultos. Pero sigue zumbando: prepotente, demagogo, petulante. ${ }^{22}$

\footnotetext{
${ }^{20}$ Una situación comparable es la que establece Dorrego, ya preso, con uno de sus custodios, un soldado correntino, con quien el gobernador vuelve a tener una actitud que parte de un reconocimiento de confianza y aparente equidad, al hablarle en su lengua aborigen materna, el guaraní.

${ }^{21}$ David Viñas, Teatro. Dorrego/Túpac Amaru, Buenos Aires, Galerna, 1985, p. 16.

22 Ibid., pp. 83 y 84.
} 
Carlos Hernán Sosa

En definitiva, esta construcción literaria del Dorrego de David Viñas -y el genitivo no es aquí ocasional-se sustenta en un juego de oposiciones binarias, cancelables por su propia naturaleza, de cuya paradoja el espectador parece no poder abstraerse: Dorrego comprende cabalmente las necesidades del pueblo, pero tiene actitudes demagógicas; Dorrego censura las zonas espurias de la vida política, pero no puede evitar caer en la corrupción; Dorrego es víctima de una conspiración por la administración del poder, pero también ingeniero de las circunstancias que precipitaron su desmoronamiento. ${ }^{23}$

Por otro lado, los acontecimientos políticos coyunturales, generalmente subrayados por la historiografía nacional argentina como los motivos concomitantes de la caída de Dorrego, se subordinan en esta reescritura de David Viñas al planteamiento del problema universal de la conducción política, que parece funcionar como uno de los mayores ejes de discusión del drama. Por ello los conflictos con los gobernadores del interior del país, las tensiones internas de una élite porteña dividida, las consecuencias funestas de la paz firmada con Brasil, las coacciones económicas gestionadas desde la metrópoli, no tienen cabida o sólo se insinúan someramente, en clara coincidencia con la preferencia por plasmar el conflicto del hombre en el poder que acabamos de indicar.

Quizá por la defensa de esta resolución, o un necesario recorte que potenciara la intensidad de la obra, en la lectura de David Viñas se dibuja el vacío

23 Martín Kohan ha encontrado una explicación próxima para cierta regularidad existente en la caracterización de los personajes, en la novelística de Viñas: "A Viñas le gustan los personajes que están 'en contra', pero que, al mismo tiempo, se encuentran muy cerca de (cuando no inmersos en) aquello de lo que están en contra". Martín Kohan, "La novela como intervención crítica: David Viñas", en Noé Jitrik [dir.], Historia crítica de la literatura argentina, vol. 9 "El oficio se afirma" (directora del volumen Sylvia Saítta), Buenos Aires, Emecé, 2004, p. 524. En vinculación con estos postulados, también resultan significativas las consideraciones sobre la narrativa de David Viñas, que presentan los siguientes autores: Juan Carlos Portantiero, Realismo y realidad en la narrativa argentina, Buenos Aires, Procyón, 1961; Humberto M. Rasi, "David Viñas, novelista y crítico comprometido", en Revista Iberoamericana, núm. 95, abriljunio, Pittsburgh, 1976, pp. 260-265; y Diógenes Fajardo Valenzuela, "David Viñas: un parricida argentino", en Amelia Royo y Martina Guzmán Pinedo [comps.], Rosismo y peronismo. De los interrogantes historiográficos a las respuestas ficcionales, Buenos Aires, Nueva Generación, 2002, pp. 71-90. 
de un gran ausente: Juan Manuel de Rosas. Si buena parte de la historiografía argentina interpretó la muerte de Dorrego, aunque naturalmente en conjunción con otros factores, como la liberación de un estorbo en la ascendente carrera política de Rosas al poder, ${ }^{24}$ en la lectura que este Dorrego practica sobre los mismos asuntos, apenas se sugiere al inminente gobernador de Buenos Aires, en una mención accesoria, cuando se alude a la "gente de don Juan Manuel". ${ }^{25}$

La concentración en un sujeto y la lectura emblemática del mismo, como "muestrario" representativo de todo un periodo histórico o de los vaivenes culturales de un momento específico, constituyen un rasgo sobresaliente de la metodología que David Viñas emplea en sus estudios críticos dedicados a la literatura argentina. En Literatura argentina y realidad politica ${ }^{26}$ un ejemplo simbólico de la producción crítica del autor, José Mármol, Lucio V. Mansilla, Gregorio de Laferrère y Armando Discépolo se instauran en ejes para este monitoreo de la lectura, y son estas mismas erecciones centrales las que generan sus

${ }^{24}$ Sirve de ejemplo la apreciación del papel desempeñado por Rosas, una vez superados los incidentes consecutivos a la caída de Dorrego - sobre todo el malestar y los levantamientos rurales ocurridos en la campaña bonaerense-, que se delinean en el comentario de Rosana Pagani, Nora Souto y Fabio Wasserman, una de las últimas versiones que tenemos del asunto: "A pesar de su ausencia del lugar de los hechos, Rosas logró apropiarse del sentido de la protesta. La intencionada identificación cultural de éste con los sectores populares rurales -que incluyó la apropiación de los símbolos enarbolados durante el alzamiento- permitió la unificación en su persona de los roles de integrador social y de protector de una comunidad que, ante las agudas transformaciones que sufría la campaña, sentía peligrar las bases de su existencia"; Rosana Pagani, Nora Souto y Fabio Wasserman, "El ascenso de Rosas al poder y el surgimiento de la Confederación (1827-1835)", en Noemí Goldman [dir.], Nueva Historia Argentina. Revolución, república, confederación (1806-1852), Buenos Aires, Sudamericana, 1998, pp. 295 y 296. Véase también, la interpretación que sobre los hechos ofrece Tulio Halperín Donghi, Historia Argentina, vol. 3, "De la revolución de independencia a la confederación rosista", Buenos Aires, Paidós, 1980, pp. 258-276.

${ }^{25}$ Viñas, op. cit., p. 22.

${ }^{26}$ David Viñas, Literatura argentina y realidad política, 2 ts., Buenos Aires, CEAL, 1994. Para mayores detalles sobre esta obra capital de Viñas, sus opciones metodológicas y una evaluación de la trascendente gravitación que ha tenido en la historia de la crítica literaria en Argentina consultar el reciente número de la revista Prismas que incluye un "Dossier" dedicado a la misma. Véase AAVV, "Dossier. Literatura argentina y realidad política, un clásico", en Prismas. Revista de historia intelectual, año 14, núm. 14, Bernal, 2010, pp. 149-189. 


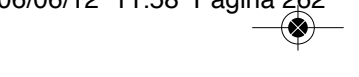

Carlos Hernán Sosa

propios - previsibles y discutibles - márgenes de sombra. Del mismo modo, la preferencia por el cúmulo de significaciones, que pueden desplegarse a partir de la aislada figura de Dorrego, genera las zonas difusas en la escritura literaria de Viñas, donde apenas se ilumina a Lavalle y donde no se admite siquiera la presencia de Rosas.

David Viñas, quien ha ponderado decisivamente el desempeño de Rosas, casi como garante del nacimiento de la literatura nacional argentina, en aquel libro señero, ante la posibilidad de representarlo literariamente opta por una sintomática elipsis - que lo muestra, otra vez, como un fiel epígono de algunas artimañas interpretativas de David Peña - mediante la cual evita, en este caso, cualquier tipo de enfrentamiento con los postulados de la historiografía liberal tradicional e incluso con los del revisionismo rosista.

V

Osvaldo Pellettieri ha señalado que "el gran ausente del teatro argentino de los años cincuenta y sesenta fue el peronismo", y que recién a partir de 1970 se produjo su "descubrimiento". ${ }^{27}$ Esta apropiación temática retrasada avanzó muchas veces por los caminos de la alusión indirecta, la parodia o el absurdo, aprovechando las distintas líneas poéticas teatrales del momento; y por ello, en sincronía con estas inquietudes, el Dorrego de Viñas puede pensarse como un emergente que iniciaba desde el género una lectura cifrada de varios elementos vinculados con el fenómeno social y político del peronismo.

Efectivamente, un estudio de los aspectos que se discuten en el Dorrego, desplazado hacia 1974, durante la tercera presidencia de Juan Domingo Perón, encuentra posibilidades de numerosos ecos temáticos, la actualización de viejos interrogantes y la apertura hacia nuevos diálogos con el pasado nacional.

${ }^{27}$ Osvaldo Pellettieri, "El peronismo y el teatro argentino del '70", en Royo y Guzmán, op. cit., p. 137. 


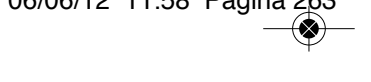

UNA REVIIIÓN DEL CAUDILLO A DOS VOCES. NOTAS SOBRE REESCRTURA E INTERTEXTUALIDAD EN EL TEATRO ...

Por este motivo, tras la imagen de Dorrego, intuimos alusiones a la figura de Perón, como el representante de un nuevo eslabón de la figura del caudillo militar que arriba al poder. El texto refuerza esta idea sobre las reduplicaciones de figuras históricas, en las premoniciones adversas del monólogo final del protagonista derrotado:

Después de mí, otro, y otro. Y otro más. iConmigo empiezan, tábanos, pero eso va a seguir! Yo soy el primero, el primer árbol sudado, pero las muertes no se van a detener: el tajo empieza a abrirse. iTajo, tajo, tajo! Una muerte, dos muertes, cuatro muertes [...]. Resbalan las muertes sobre el sudor. ¿Cómo? Como árboles que irán muriendo: uno después de otro. Tábanos. Tábanos, Dorrego. Yo, el primero, claro. Pero esa larga fila no va a terminar nunca $[\ldots] .^{28}$

La jura en la gobernación, el menosprecio hacia la Iglesia, la alusión peyorativa sobre el masivo número de votantes, el saludo desde la ventana-balcón (con la cual se insinúa el balcón de la Casa Rosada de gobierno), el ataque por supuesta demagogia y personalismo político, el insulto de Dorrego a sus antiguos adeptos con el calificativo "montoneros" (nombre que recibieron tanto las milicias populares del siglo XIX , como una de las facciones políicas del peronismo setentista en Argentina), son piezas clave que admitirían la organización de una red de interpretaciones oblicuas -sumamente críticas y deslegitimadoras-del contexto del peronismo, precisamente en el periodo previo a la muerte de su máximo líder.

La convicción sobre la urgente mirada hacia el pasado con el fin de hacer un diagnóstico preciso de los avatares que derivarían en el presente, como paso previo para desplegar un programa político capaz de subsanar las falencias históricamente retardatarias del afianzamiento de una cultura nacional argentina -uno de los objetivos cardinales del grupo intelectual de la revista Contorno del

${ }^{28}$ Viñas, Teatro. Dorrego/Túpac Amaru..., p. 84. 
Carlos Hernán Sosa

que formó parte el autor $-{ }^{29}$ parecerían estar operando todavía en la elaboración ficcional, y políticamente activa, del Dorrego de David Viñas. ${ }^{30}$

Y vapuleada por estos propósitos, perdura en los lectores una pregunta subyacente, que todo lo moviliza y todo lo cuestiona: ¿dónde está la verdad? - un substrato escéptico que, por supuesto, no tenía cabida en el persuasivo voluntarismo revisionista de David Peña, en los albores del siglo xx-. Tras su aparente búsqueda, pues la obra de David Viñas sí arranca con un epígrafe de pretensiones reparadoras tomado de George Steiner -"En la tragedia un solo caso individual de injusticia cuestiona la pretensión general de orden"-, no se conservan más que manotazos sin respuestas. Perdura entonces el reconocimiento de un balbuceo impreciso y direccionado de la historia - tanto la universal como la argentina-, de carácter iterativo además - he aquí otra deuda con el fundador Peña-, que si bien no esconde cierta visión desmitificadora sobre la construcción del pasado argentino, no puede escapar al rol de agente aleccionador para encauzar una contemporaneidad, cuyas resoluciones en el orden políico y social - peronistas-, indudablemente, a David Viñas entonces no le satisfacían. Por su parte, persiguiendo otros propósitos pero con la misma actitud manipuladora, David Peña le había dedicado con solemnidad su obra "A la señora Felicia Dorrego de del Solar. Homenaje", pues era apremiante en él la necesidad del incipiente panegírico revisionista que debía honrar a los "injustamente olvidados",

${ }^{29}$ Una prolija revisión de la trayectoria intelectual del grupo nucleado en torno de la revista Contorno, en el campo intelectual argentino de la década de 1950, es la que presentan Nora Avaro y Analía Capdevila, Denuncialistas. Literatura y polémica en los '50, Buenos Aires, Santiago Arcos, 2004, donde incluyen una antología temática de los artículos de la revista con precisas introducciones. Para una interpretación de la actitud revisionista de los intelectuales argentinos de la década de 1970, consultar el artículo de Fernando Devoto, "Reflexiones en torno de la izquierda nacional y la historiografía argentina", en Fernando Devoto y Nora Pagano [eds.], La bistoriografía académica y la bistoriografía militante en Argentina y Uruguay, Buenos Aires, Biblos, 2004, pp. 107-131.

${ }^{30} \mathrm{Con}$ el fin de evaluar el papel que cubre la política en el proyecto crítico-literario de David Viñas, son muy útiles las reflexiones integradoras del artículo de Julio Schvartzman, "David Viñas: la crítica como epopeya", en Noé Jitrik [dir.], Historia crítica de la literatura argentina, vol. 10 "La irrupción de la crítica" (directora del volumen Susana Cella), Buenos Aires, Emecé, 1999, pp. $147-180$ 
desde una tesitura monolítica que pudiese actuar como decisivo contrapeso de la versión canónica y liberal de la historia nacional argentina que se anhelaba desbancar.

Ahora bien, es probable que la relectura actualizada de estos dos epígrafes, mediante las discusiones que las propias obras potencian y la perspectiva del tiempo transcurrido, nos dé hoy un saldo negativo - $\mathrm{O}$ al menos sospechosoque atenúe los afanes revisionistas que ambas perseguían. Quizá hoy sólo resuenen como actos de alerta - o de disculpas previas-antes que como un intento de desenmascaramiento que aparece algo envejecido; puesto que hemos aprendido - tras estos recurrentes ensayos de lectura-a ser más cautos y perspicaces a la hora de examinar nuestro pasado, al punto que hasta podemos -y debiéramos hacerlo- permitirnos también desconfiar de estas oportunas relecturas sobre Manuel Dorrego, tan profundas y selectivamente enraizadas en el conocimiento de la historia nacional argentina.

Recibido: 29 de abril, 2011. Aceptado: 19 de enero, 2012.

\section{BibLIOGRAFÍA}

AAVV, "Dossier. Literatura argentina y realidad política, un clásico", en Prismas. Revista de historia intelectual, año 14, núm. 14, Bernal, 2010, pp. 149189.

Avaro, Nora y Analía Capdevila, Denuncialistas. Literatura y polémica en los '50, Buenos Aires, Santiago Arcos, 2004.

Barba, Enrique M., Unitarismo, federalismo, rosismo, Buenos Aires, Ceal, 1982. Blanco Amores de Pageila, Ángela, Motivaciones del teatro argentino del siglo XX, Buenos Aires, Ediciones Culturales Argentinas, 1983.

Bosch, Mariano, Historia de los orígenes del teatro nacional argentino y la época de Pablo Podestá, Buenos Aires, Solar/Hachette, 1969. 
Carlos Hernán Sosa

CASTAGNino, Raúl HÉCTOR, Literatura dramática argentina. 1717-1967, Buenos Aires, Pleamar, 1968.

Castellanos, Joaquín, "David Peña”, en Obras literarias, Buenos Aires, Imprenta del Honorable Senado de la Nación Argentina, 2000, pp. 57-62.

Ciementi, Hebe, Rosas en la historia nacional, Buenos Aires, La Pléyade, 1970.

Devoto, Fernando y Nora Pagano [eds.], La historiografía académica y la historiografía militante en Argentina y Uruguay, Buenos Aires, Biblos, 2004.

Fajardo Valenzuela, Diógenes, "David Viñas: un parricida argentino", en Amelia Royo y Martina Guzmán Pinedo [comps.], Rosismo y peronismo. De los interrogantes historiográficos a las respuestas ficcionales, Buenos Aires, Nueva Generación, 2002, pp. 71-90.

Halperín Donghi, Tulio, Historia Argentina, vol. 3, "De la revolución de independencia a la confederación rosista”, Buenos Aires, Paidós, 1980.

Jauretche, Arturo, Política nacional y revisionismo histórico, Buenos Aires, Peña Lillo editor, 1982.

KoHAN, MarTín, "La novela como intervención crítica: David Viñas", en Noé Jitrik [dir.], Historia crítica de la literatura argentina, vol. 9, "El oficio se afirma" (directora del volumen Sylvia Saítta), Buenos Aires, Emecé, 2004, pp. 523-541.

LEVENE, RiCARDO, "La sublevación del $1^{\circ}$ de diciembre de 1828 y los gobiernos de Lavalle y Viamonte", en Academia Nacional de la Historia, Historia de la Nación Argentina, primera sección, Buenos Aires, El Ateneo, 1950, vol. VII, pp. $227-271$.

Ortega Peña, Rodolfo y Eduardo luis Duhalde, El asesinato de Dorrego. Poder, oligarquía y penetración extranjera en el Río de la Plata, Buenos Aires, Peña Lillo editor, 1973.

Pagani, Rosana, Nora Souto y Fabio Wasserman, "El ascenso de Rosas al poder y el surgimiento de la Confederación (1827-1835)", en Noemí Goldman [dir.], Nueva Historia Argentina. Revolución, república, confederación (18061852), Buenos Aires, Sudamericana, 1998, pp. 283-321.

Pavis, Patrice, Diccionario del teatro. Dramaturgia, estética, semiología, Buenos Aires, Paidós, 2003. 
Pellettieri, Osvaldo, "El peronismo y el teatro argentino del '70", en Amelia Royo y Martina Guzmán Pinedo [comps.], Rosismo y peronismo. De los interrogantes historiográficos a las respuestas ficcionales, Buenos Aires, Nueva Generación, 2002, pp. 137-147.

PeÑa, David, "Facundo. Drama histórico en cuatro actos", en Bambalinas. Revista de actualidades teatrales y artísticas, año I, núm. 38, Buenos Aires, 21 de diciembre, 1918.

, "Dorrego. Drama histórico en cuatro actos", en Bambalinas. Revista actualidades teatrales y artísticas, año II, núm. 75, Buenos Aires, 13 de septiembre, 1919. , Juan Facundo Quiroga, Buenos Aires, Hyspamérica, 1986.

Portantiero, Juan Carlos, Realismo y realidad en la narrativa argentina, Buenos Aires, Procyón, 1961.

Rasi, HumberTo M., "David Viñas, novelista y crítico comprometido", en Revista Iberoamericana, núm. 95, abril-junio, Pittsburgh, 1976, pp. 260-265.

RosA, José MaríA, Historia Argentina, t. IV, "Unitarios y federales", Buenos Aires, Oriente, 1965.

RuBione, Alfredo, "Enrique Larreta, Manuel Gálvez y la novela histórica", en Noé Jitrik [dir.], Historia crítica de la literatura argentina, vol. 6, "El imperio realista" (directora del volumen María Teresa Gramuglio), Buenos Aires, Emecé, 2002, pp. 271-298.

Schvartzman, Julio, "David Viñas: la crítica como epopeya", en Noé Jitrik [dir.], Historia crítica de la literatura argentina, vol. 10, "La irrupción de la crítica" (directora del volumen Susana Cella), Buenos Aires, Emecé, 1999, pp. $147-180$.

SHumway, Nicolás, La invención de la Argentina. Historia de una idea, Buenos Aires, Emecé, 1995.

ViñAs, David, Teatro. Dorrego/Túpac Amaru, Buenos Aires, Galerna, 1985. CEAL, 1994. , Literatura argentina y realidad política, 2 ts., Buenos Aires, 